\title{
The Interpersonal Metafunction Analysis of Barack Obama's
}

\section{Victory Speech}

\author{
Ruijuan Ye \\ Guangdong Pharmaceutical University, Guangzhou Guangdong, 510006 \\ E-mail: leafnn@126.com
}

\begin{abstract}
This paper carries on a tentative interpersonal metafunction analysis of Barack Obama's Victory Speech from the Interpersonal Metafunction, which aims to help readers understand and evaluate the speech regarding its suitability, thus to provide some guidance for readers to make better speeches.

This study has promising implications for speeches as follows: (1) Positive declarative clauses are recommended to convey information and convince the audiences with positive facts. (2) Modal verbal operators with high modal commitment can show the addresser's firm determination to finish tasks and build up the addresser's authority. (3) The frequent applications of "we" and "we"-"you"-"we" pattern help to create an intimate dialogic style, which can shorten the distance between the addresser and the audience and further persuade the audience to share the same proposal of the addresser.
\end{abstract}

Keywords: Discourse Analysis, The Interpersonal Metafunction, Speech.

\section{Introduction}

Halliday (1970) states that the context of a situation is arranged in three categories: field, tenor and mode. Corresponding to that, Halliday analyzes language into three broad Metafunctions: Experiential, Interpersonal and Textual Metafunctions. Each of the three Metafunctions is about a different aspect of the world and concerned with a different mode of meaning of clauses, of which, according to Halliday (1994:68), it is through the Interpersonal Metafunction that users of language establish, negotiate and assume their position in social relationships, and it is concerned with clauses as exchange.

In the past decades, a great number of research papers and books on Interpersonal Analysis have been published. With this regard, we can mention An Interpersonal Analysis of Du Mu's "Qingming" and its Translated Versions (Huang 2002), and "On the Interpersonal Meaning of Reflexive Expressions in Autobiography" (Li 2001). And recent years have witnessed discourse analysts' increasing interest in discourse analysis of speech, which mainly concerns the relationship between the form and meaning. In functional grammar, "choice is meaning" is a widely accepted principle and form is the realization of meaning in discourse analysis (Huang 1998). To fulfill their communicative purposes of their speeches, the addressers try every potential technique and frequently and widely use figures of language to make good speeches (see Li 2004:38). As a result, speech holds its unique features in terms of language use and becomes a special discourse type.

Following Systemic Functional Grammar, the paper is written to help readers to understand Barack Obama's Victory Speech and evaluate it with regard to its suitability with the analysis from the Interpersonal Metafunction, which is hoped to provide guidance for readers about how to make better speeches to achieve their purposes.

\section{Barack Obama's Victory Speech}

On Nov. 4 2008, U.S. Democratic Party candidate Barack Obama claimed victory in the U.S. presidential election, addressing about 150,000 supporters at his election night party at Grant Park in downtown Chicago, Illinois with the great speech titled "change has come to America." In his victory speech, Obama congratulated his Republican rival John McCain and his running mate Sarah Palin for their achievements in the presidential campaign; He also praised his campaign team as one of the best in history and thanked his family, including his grandmother who passed away on Monday, for their support during the presidential campaign. Obama also mentioned that the road ahead would be long and hard with many challenges waiting to be tackled.

The speech touched on the nation's state of affairs and the direction of the new government would be heading, pushing focus away from Obama himself and re-directing it back to the people, talking about what really mattered most without the fat. Best of all, it was inspirational, telling the nation that even though the country was probably in its darkest days, there was hope; there was a chance to turn it around and climb back into the light. It was such an eloquent, humble, and concise speech that America News Intermediary compared it to Lincoln 
Memorial Address "I have a dream". As one of the most successful speeches in America's history, Barack Obama's Victory Speech maintains most of the prominent features of speeches as a special discourse type. The above factors make contributions to the reliability and validity of the research result of this paper.

\section{The Interpersonal Metafunction Analysis of Barack Obama's Victory Speech}

The Interpersonal Metafunction of a speech represents the way the addresser and the audience interact, the use of language to establish and maintain relations with them, to influence their behavior, to express our own viewpoint on things in the world, and to elicit or change theirs. It mainly concerns the Roles of Addressers and Audience, Mood and Modality.

To help readers to understand Barack Obama's Victory Speech and make comments on the speech about whether it is an effective discourse for its own purpose, the following analysis of the speech from the perspective of the Interpersonal Metafunction mainly involves the analysis of Mood, Modality and Pronoun.

\section{$3.1 \mathrm{Mood}$}

To keep communication going, a component is indispensable for carrying out the Interpersonal Metafunction of the clause as exchange in English. This component is called Mood and is made up of Subject and Finite (see Thompson 2000:41). To quote Halliday (1994:76), "the Subject supplies the rest of what it takes to form a proposition, namely, something by reference to which the proposition can be affirmed or denied". The Finite refers to the first functional element of the verbal group.

When it comes to the roles of addressers and audience, the most fundamental purposes in any exchange are giving or demanding information and goods and services. According to Halliday (1994:69), in any communicative language, there are four basic speech roles: giving information, demanding information, giving goods and services and demanding goods and services. The usual labels for these functions are Statement, Question, Offer and Command. In which, the function of Statement is closely associated with particular grammatical structure, that is, the declarative clauses; Question is related to interrogative clauses; and Command is associated with imperative clauses. The ordering of Subject and Finite (two elements of the Mood system of the clause) in the clause plays an indispensable role in signaling speech roles in that it can show whether the clause is indicative or imperative. The Subject ${ }^{\wedge}$ Finite (here " $\wedge$ " is the symbol for "followed by") ordering of the clauses differs declarative clauses $\left(\right.$ Subject ${ }^{\wedge}$ Finite) from interrogative clauses (Finite ${ }^{\wedge}$ Subject).

The analysis of the identifying of Subject and Finite shows that the ordering of Subject and Finite in most clauses of Barack Obama's Victory Speech is Subject ${ }^{\wedge}$ Finite pattern, which signals that most of the clauses in the speech are declarative clauses. By statistics, of 108 major clauses in the data, all together 101 clauses are declarative clauses, taking up $93.5 \%$ of the speech; 5 clauses are imperative ones and only two are interrogative clauses.

The purpose of a speech is to express the addresser's viewpoint on things in the world, to elicit or change the audience's attitudes and to arouse the audiences' passion to share the same proposal of the addresser. Particularly in a political speech, as a dilly carrying on a political mission, it is vital and apparent for the addresser to give information and demand services. On one hand, the addresser hopes to offer certain messages to the audience showing his political attitude and assumption. On the other hand, he tries to demand and arouse the audience to take action to follow his instruction. Therefore, complete declarative clauses generally dominate in a political speech; imperative clauses come next to them; and interrogative clauses are the last choices for the reason that they may make a speech less solemn, less convincing and persuasive. With the above regard, the dominant appearances of 101 declarative clauses in Barack Obama's Victory Speech are successful in that they are functioned as statements to give as much as possible information to the audience, with which he succeeded in recalling his presidential election campaign, expressing his gratitude to his supporters, making promises and inspiring the audience to go through the difficulties with the whole nation.

Imperative clause also plays an important role in a speech in that it can appeal the audience to follow the addresser's instruction; in that it can also help to build up the authority of the addresser. While in a speech, it is more significant for the addresser to build up an equal and mutual reliant relationship with the audience. Even though we mentioned above that the function of command is closely associated with imperative clauses, while Halliday (1970) states that the two kinds of messages conveyed by imperative clauses are: one is to command others to do something, the other is to invite the audience to do something together. The latter is always effected by the format of "Let's". With references to 5 imperative clauses in the data, Barack Obama chose "let us" imperative clauses, which indicate that he is not giving a direct command but making a suggestion, conviction and persuasion. With the applications of five "let us" imperative clauses, Obama successfully shortens the 
distance between him and the audience and further to call on them to take actions together with him to overcome the difficulties. In this way, the 5 imperative clauses made Barack Obama's Victory Speech more moving, appealing and inspiring to the audience, which can be showed in the following two examples:

(1)So let us summon a new spirit of patriotism; of service and responsibility where each of us resolves to pitch in and work harder and look after not only ourselves, but each other.

(2) Let us remember that if this financial crisis taught us anything, it's that we cannot have a thriving Wall Street while Main Street suffers.

With 5 imperative clauses in the data, Obama maintains an equal and reliant relation with the audience, which is helpful in moving the audience with emotion. Thus he can win extensive supporters and advocates.

Even interrogative clause is not a widespread choice in a speech, but the appropriate usage of interrogative clause can help to create an intimate dialogic style. In the above style, the audience consider that they are friends with the addresser and naturally share his same proposal. For this, we can refer to the two interrogative clauses in Barack Obama's Victory Speech:

(3)If our children should live to see the next century, if my daughters should be lucky to live as long as Ann Nixon Cooper, what change will they see?

(4)What progress will we have made?

Apparently, Obama doesn't look forward to the audience's answers. The sentences were not only used to attract the audience's attention, but also to emphasize in order to make the audience think and rouse their passion for overcoming the current difficulties.

\subsection{Modality}

Halliday (2000) states that modality also plays an important role in carrying out the interpersonal metafunction of clauses showing to what degree the proposition is valid. Modality refers to the space between "yes" and "no", showing the speaker's judgments of the probabilities or the obligations involved in what she is saying. According to Thompson (2000:57), Modality consists of Modalisation and Modulation. The former relates to the speaker's judgment of the validity of the proposition, and covers the scale of in terms of probability (possible-probable-certain) and usuality (sometimes-usually-always). The latter relates to how confident the speaker can be in the eventual success of the exchange, and it includes the degree of obligation (allowed-supposed-required) and the inclination (willing-keen-determined). There are a number of ways to realize modality, such as non-verbal and verbal, through non-deliberate features and deliberate features, among the above expressive ways, one of the most common ways for the realization of modality as a function of the Mood is through modal verbal operators. When realized by modal verbal operators, Modality involves degrees and scales about the validity of a proposition, which coins the term "Modal Commitment". According to Halliday (1994), three basic values of modal commitment are high, median and low on the scale. And different scales of modal commitment lead to different meanings.

By statistics, 55 modal verbal operators are adopted in Barack Obama's Victory Speech, of which, the most frequently adopted ones are as the following: "will" turns up for 18 times, "can" is adopted for 22 times, "must" turns up for 4 times.

Being a marker of the future tense, "Will" is adopted for 7 times in Barack Obama's Victory Speech to predict the future, which can be shown as the following examples:

(5) The road ahead will be long.

(6) Our climb will be steep.

"Will" can also be used as a modal verbal operator to show "strong wish and determination", which is adopted for 11 times in Barack Obama's Victory Speech. The above mentioned examples can be seen partially as the following sentence:

(7) We may not get there in one year or even in one term. But, America, I have never been more hopeful than I am tonight that we will get there.

(8) To those who would tear the world down: We will defeat you.

As is mentioned above, different scales of modal commitment lead to different meanings. "Will", which represents a higher scale of modal commitment; signals a higher degree of certainty about the validity of a proposition. Thus the constant use of "will" in the data is successful in showing Barack Obama's strong mind and keen desire to lead American to go through the difficulties. Meanwhile, the higher modal commitment of "will" 
further confirms that more actions will be definitely taken in the future.

Similarly, on one hand, "can" representing a low value modulation. Permission of "can" is seen as the lowest degree of pressure, opening the possibility for the other person to do the action but leaving the decision to them; with regard to this, Obama uses "can" to weaken his authority, to shorten the distance between him and the audience and not to force and command them to follow his instruction. On the other hand, the semantic meaning of "can" is "have the ability to do something", which is showed by the most repeated significant sentences "Yes we can" in the speech. The constant applications of "can" here is to encourage American to believe in themselves to be confident that they have the ability to do anything, telling the nation that even though the country was probably in its darkest days, there was hope; there was a chance to turn it around and climb back into the light.

"Must", representing the highest scale of modal commitment; signals the highest degree of pressure on the other person to carry out a command. And thus "must" is sometimes adopted in a political speech in that the addresser need to show his firm determination, to call on the audience to be determined to take action to achieve their common objective. There is no exception in Barack Obama's Victory Speech, the application of "must" in the data can be showed in the following sentence:

(9)What we've already achieved gives us hope for what we can and must achieve tomorrow.

Here, "must" helps to show Barack Obama's firm determination to overcome the difficulties and call on the American to take strong actions to achieve their target.

\subsection{Personal Pronoun}

According to Li (2002), personal pronouns have the interpersonal function in discourse. That is because they establish a certain relationship between the addresser and the audience in a speech. Thus, Personal pronouns are viewed as another way of carrying interpersonal meaning apart from Mood and Modality. Generally, the first personal pronoun "I "and "we" refer to the addresser, the second personal pronoun "you" refers to the person(s) spoken to. And the application of personal pronouns in Barack Obama's Victory Speech can be shown clearly in the following Figure 1.

Insert Figure 1 Here

From the above Figure, we can see that the first personal pronoun takes up $75 \%$, of which the plural form "we" and its anamorphous "us" and "our" occupy 56\%; the first single personal pronoun "I" takes up 19\%. Whereas the second personal pronoun "you" occupies $13 \%$ and the third personal pronoun comes next to it.

Examining the data, we can see that Obama use "I" to speak of his election campaign and express his gratitude. For example:

(10)To my sister Maya, my sister Alma, all my other brothers and sisters, thank you so much for all the support that you've given me. I am grateful to them.

(11)To the best campaign team ever assembled in the history of politics you made this happen, and I am forever grateful for what you've sacrificed to get it done.

From the above sentences, we can see that the application of "I" here successfully describes the new elected president into a sincere person who will remember the gratitude and try to repay it.

As is stated above, the plural form of the first personal pronoun "we" and its anamorphous appear at a high rate as personal pronouns in Barack Obama's Victory Speech. In Functional Grammar, "we" and its anamorphous can be both "inclusive" and "exclusive", in which, the former is equal to "I and you (the person(s) spoken to)", which holds emotional effectiveness thus to greatly shorten the distance between the speaker and audience in that it can make them sense that they share a common objective. The latter, that is "exclusive we" stands for "I and others" not "I and you (the person(s) spoken to), which implies a sense of authority, making the audience experience a feeling that the addresser and his team are strong enough to knockdown everything.

By statistics, in Barack Obama's Victory Speech, "we" turns up for 40 times, of which 33 are inclusive ones, 7 ones are exclusive, which can be seen partially in the following sentences:

(12)We are, and always will be, the united states of American.

(13)It's the answer that led those who've been told for so long by so many to be cynical and fearful and doubtful about what we can achieve to put their hands on the arc of history and bend it once more toward the hope of a better day.

In the above sentences 12 and 13 and the like, "we", suggesting "I and you (the person(s) spoken to)", paint Obama into a common citizen as hundreds of thousands of Americans, which suggest that he and all the 
Americans are in the same boat. In this way, Obama successfully shortens the distance between him and the audience and maintains an equal and reliant relationship between them, thus greatly helps to persuade the audience to share his same proposal that is to take actions to go through the difficulties even though there are two wars, a planet in peril and the worst financial crisis in a century.

Referring to the exclusive "we" in the data, we can take the following sentence as an example:

(14)To those -- to those who would tear the world down: We will defeat you. To those who seek peace and security: We support you.

Here, "we", which holds an exclusive meaning "I and others (his government)", signals that Obama and his government are a strong team with high spirit, holding powerful authority and determination to protect their citizen and lead their nation to a bright future. So the exclusive "we" help Obama to win Americans' great confidence in the new elected government.

With reference to the second personal pronoun "you", Li (2001) states that "you" can make a significant role in the speech, because it can help to create a dialogic style in the speech, maintaining a close intimate relation between the addresser and the audience, and thus to ensure the effective interaction of the addresser and the audience in a speech. The above mentioned can be seen in the following sentence:

(15) And I know you didn't do this just to win an election. And I know you didn't do it for me. You did it because you understand the enormity of the task that lies ahead.

Here, "you" is not only used to attract the audience's attention but also make them feel that they are making a dialogue with their friend (the addresses). With "you" Obama shows his care and respect to the audience, thus a close intimate relation was maintained and the audience is likely to share the same attitude and assumption of the addressers.

To sum up, “we”-“you”-“we” pattern in Barack Obama's Victory Speech successfully creates a dialogic style, which successfully shortens the distance between Obama and other Americans, and that is significant for Obama to win widespread support for his new government.

\section{The Main Findings of the Research and the Implications.}

In summary, the research so far shows that, from the perspective of the Interpersonal Metafunction, positive declarative clauses dominate Barack Obama's Victory Speech; imperative clauses are in the second position; "will", "can" and "must" turn up frequently as modal verbal operators to carry on the modality in the speech; the first personal pronoun and its anamorphous turn up mostly in Barack Obama's Victory Speech, the second personal pronoun "you" come next.

This paper can provide some guidance for readers to make better speeches as follows: (1) Positive declarative clauses are recommended to convey as many as possible messages to the audience and convince the audience with fact; appropriate application of imperative clauses are useful in making persuasion and suggestion. (2) Modal verbal operators with higher or highest modal commitment can show the addresser's firm determination to finish the task, and "can" is helpful to encourage the audience to have confidence in their ability. (3) Choosing "We" to be the personal pronoun and applying "we"-"you" -"we" pattern can help to create an intimate dialogic style and shorten the distance between the addresser and the audience, which can further persuade the audience to share the same proposal of the addresser.

\section{References}

Chen, Youjun. (2006). The Interpersonal Analysis of Bush's inaugural, Changchun: Northeast China Normal University.

Guan, Shuhong. (2005). The Interpersonal Metafunction of Political Speech. Journal of Inner Mongolia Agricultural University(Social Science Edition), (4).

Halliday, M. A. K. (1970). Language structure and language function. In Lyons, J. (ed.) New Horizons in Linguistics. Harmondsworth: Penguin,:140-165.

Halliday, M. A. K. (1988). An Introduction to Functional Grammar (2nd ed.). London: Edward Arnold, 1994. http://www.douban.com/group/topic/4572666/

Hu, Zhuanglin. (2000). On Functional Grammer. Beijing: Foreign Language Teaching and Research.

Huang, Guowen. (2002). An Interpersonal Analysis of Du Mu's "Qingming" and its Translated Versions. Foreign language teaching, (3). 
Huang, Guowen. On Discourse Analysis. Changsha: Hunan Educational Press.

Li, Yuanshou. (2004). Speech and eloquence. Wuhan: Huazhong University of Science and Technology press, Li, Zhanzi. (2001). On the Interpersonal Meaning of Reflexive Expressions in Autobiography Foreign Language Teaching,(3).

Li, Zhanzi. (2004). The Interpersonal Study on Discouse. Shanghai: Shanghai Foreign Language Teaching.

Thompson, G. (1996/2000). Introducing Functional Gramma. Beijing: Foreign Language Teaching and Research Press.

Wang, Hongyang, Cheng, Chunsong. (2007). Modality Perspective: A Contrastive Study of English Political Speeches and Academic Speeches. Foreign Languages and Their Teaching, (5).

\begin{tabular}{|l|l|l|l|l|l|l|l|l|l|}
\hline $\begin{array}{l}\text { Personal } \\
\text { Pronoun }\end{array}$ & we & I & us & our & you & your & he/she & they & total \\
\hline times & 40 & 25 & 11 & 22 & 13 & 4 & 13 & 3 & 131 \\
\hline Proportion & $31 \%$ & $19 \%$ & $8 \%$ & $17 \%$ & $10 \%$ & $3 \%$ & $10 \%$ & $2 \%$ & \\
\hline
\end{tabular}

Figure 1. The application of personal pronouns 